\title{
En busca de la democracia. Pensando la movilización social en tiempos de grandes cambios
}

\author{
Joel Trujillo Pérez*
}

Para un científico social contemporáneo es imposible pensar la realidad social concreta sin, al menos, considerar a los movimientos sociales como parte constitutiva de su esquema de análisis. Más allá de si este fenómeno inicia con la modernidad como propone Charles Tilly, o si han venido a sustituir a los movimientos de clase, se puede decir que ya son parte permanente y constitutiva de la realidad política concurrente. Y es por lo que deben ser sujetos a rigurosos análisis desde las más diversas ópticas, ya sean filosóficas, politológicas, sociológicas o antropológicas, atendiendo más que a la disciplina, al mejor enfoque que nos permita comprenderlos integralmente.

Esta obra colectiva, coordinada por René TorresRuiz de la Universidad Iberoamericana, nos acerca justamente a una perspectiva interdisciplinaria donde el movimiento permite jugar no sólo con las ópticas teóricas, sino también las disciplinares. Así, la línea conductual del texto subyace en los núcleos problemáticos de la democracia liberal y representativa como forma de gobierno, así como en los

- Departamento de Ciencias Políticas y Sociales, Universidad Iberoamericana, Ciudad de México.

Antropólogo social por la Escuela Nacional de Antropología e Historia (ENAH); maestrante en Sociología en la Universidad Iberoamericana Ciudad de México (UIA-CDMX). Correo electrónico: joel. trujillo@correo.uia. $\mathrm{mX}$ ORCID: 0000-00034789-7778. sujetos que emergen de las propuestas incumplidas de ella. Ya sean: etnias, jóve-

Fecha de recepción: II de septiembre de 2020. Fecha de aceptación: 17 de noviembre de 2020.
Torres-Ruiz, René. (Coord.) (2020). En busca de la democracia. Pensando la movilización social en tiempos de grandes cambios. Ciudad de México: Universidad Iberoamericana Ciudad de México. 
nes "indignados", la primavera árabe, trabajadoras sexuales o el Movimiento por la Paz con Justicia y Dignidad (MPJD), todos los movimientos y sujetos comparten la desprotección tanto del Estado como de la democracia, así como la profundización de las lógicas del fundamentalismo del mercado. Como resultado, buscan tomar caminos propios, lo cual permite pensar la democracia como problema, no como solución (p. 13). En este punto radica la importancia del libro, pues más allá de definiciones normativas sobre la democracia, nos enfrentamos a su búsqueda real y concreta por distintos medios que la innovan, la rebasan y, en ocasiones, la niegan para afirmarse a sí mismos.

Además, el conjunto de capítulos posee al menos tres características comunes que lo hacen necesario para entender los movimientos sociales contemporáneos. El primero es el especial énfasis en los elementos "subjetivos", biográficos o repertorios cotidianos más allá de la estructura o la acción. En éste recae la riqueza de los textos, pues cuestiona y debate los alcances de la democracia desde los más diversos grupos que la han definido más allá de lo institucional. Por ello, algunos de ellos no sólo la cuestionan, sino que la rechazan.

Aquí se presenta el segundo punto que subyace al total de los capítulos que es, de fondo, el cuestionamiento de las ambiguas relaciones entre la democracia liberal y el capitalismo neoliberal, el cual se ha conjugado con las instituciones representativas. Ejemplos de lo anterior son el movimiento neozapatista en México, los indignados en España u Ocuppy Wallstreet en el corazón del mercado contemporáneo que es Nueva York, en Estados Unidos. Entonces, la conciencia de clase - elemento que se había dejado de lado- y la sensación de exclusión de dos sistemas - uno político y otro económico que, sin embargo, convergen-, generan alternativas autogestivas que, a través de la propia subjetividad y la indignación, se construyen desde la cotidianidad. Finalmente, el tercer punto es que 
muchos de estos movimientos no buscan complementar la democracia, sino salir de ella a partir del activismo y la praxis en la vida cotidiana, también alejándose de la propia institucionalización del movimiento.

Bajo estos argumentos, los nueve capítulos del libro —más la presentación del coordinador a modo de introducción- nos llevan a conocer las fallas en la democracia que han dado paso a múltiples respuestas que, si bien pueden ser llamadas "movimientos sociales", cada autor o autora nos permite observar la especificidad y la diferencia, no tanto las generalidades. De esta premisa parte Torres-Ruiz al señalar que la brecha cada vez mayor entre sociedad civil y sociedad política ha traído como consecuencia múltiples rupturas, en ocasiones irreconciliables. En la presentación del libro denota la democracia ya no como concepto normativo, sino como proceso realmente existente que, en la mayoría de las ocasiones, proviene de sujetos con demandas que han sido históricamente negadas. Así, surgen acciones de tipo contencioso que tienen como principal objetivo publicitar enojo, indignación, rabia, no sólo en el plano nacional sino también en el internacional.

Ejemplo de ello es la oleada de movimientos en España, Turquía, Estados Unidos, que surgió después de la crisis económica de 2008, donde los jóvenes en las redes sociales virtuales fueron los principales protagonistas. Expresados por Pleyers en "Los movimientos de las plazas en el decenio 2010", el alter-activismo o activismo compartido entre plazas, vida cotidiana y redes sociales — siguiendo la tesis de Castells (2012) — muestra cómo la democracia ha salido de las instituciones electorales y se ha convertido en una actitud cotidiana. Una democracia representativa que no los representa. Así, también han salido de la clásica denominación de movimientos sociales, pues no sólo se encuentran en la acción o la estructura, sino que se fundamentan en la experiencia que permea la historia del individuo y el 
colectivo: la biografía. Es decir, se pasa del movimiento a los símbolos, a las emociones y a la democratización de los valores personales. Asimismo, un hallazgo importante recae en el distanciamiento no sólo hacia las instituciones clásicas a las que ven obsoletas, sino también de las organizaciones civiles para dar paso a la vinculación más allá de estructuras predefinidas, a la reflexión colectiva, no así "formal".

En tanto, el segundo capítulo que corre por cuenta de Joan Subirats, el cual contiene la sugerente propuesta acerca de la pérdida de legitimidad en el sistema político, lo cual no da lugar a una nueva política en sí, sino a nuevos tiempos, valores y formas de entender la política. En ella, la diversidad, la intercomunicación, la obsolescencia de los sistemas político y económico de corte liberal y la difuminación entre lo global y lo local, con lo que han creado percepciones de cambio político. En consecuencia, ha dado lugar al cambio de percepciones que se enfrentan a instituciones, por lo cual se les puede considerar una "netocracia", donde las redes y la flexibilidad han mostrado principalmente el cambio corto de ciclo donde principalmente se puede ver, de manera paralela, el cambio de actores, la transición concurrente, no sin dudas razonables.

Ya en el plano nacional, el tercer capítulo lo entrega Armando Bartra, quien, desde una posición mayormente filosófica, hace que "Los movimientos sociales como experiencias desnudas" traten de alejarse del positivismo y el revisionismo histórico para dar cuenta del levantamiento neozapatista de 1994 como irrupción —no interrupción- del mundo. Es decir, que la estructura de una narración pueda hacerse transmisible y experimentable por otros. Esto es una experiencia desnuda que se ha buscado transmitir: la explotación, la discriminación, la segregación estructural tanto del Estado como del fundamentalismo neoliberal que no pueden pensarse por separado. Entonces, de lo arbitrario y lo contingente se busca recuperar el camino de la comu- 
nalidad, esto es, pensarse colectivamente en oposición al individualismo económico y político liberal para recuperar la historicidad a través del deseo, lo arbitrario y las memorias como proyecto político más allá de la estructura.

El cuarto capítulo lo entregan Poma y Gravante, titulado "Subjetividad y democracia", que pone especial énfasis en la reelaboración de valores con consecuencias biográficas. Esto es, la dimensión psicosocial de los movimientos sociales en el alejamiento de la democracia clásica y el cambio hacia una nueva idea de democracia a partir de las subjetividades individuales que marca las experiencias y la experimentación. Tal es el fundamento que se opone tanto al liberalismo que busca la racionalidad, como a la propia teoría de la acción en los movimientos sociales que deja, donde ha trivializado e ignorado, por ejemplo, las emociones (p. 106). En este sentido, los autores también parten de la dimensión particularista y de los cambios en la vida cotidiana para pensar en la "pospolítica" o, lo que es lo mismo, el rechazo de la política institucional en aras de generar pequeños cambios en la vida cotidiana que se vinculen a transformaciones en la interpretación y el imaginario de la democracia para crear otro mundo.

En tanto, la antropóloga Martha Lamas hace un recuento de la política de la identidad en trabajadoras sexuales de Ciudad de México que lograron convertirse en una red nacional para apoyar la búsqueda de derechos laborales ante la extorsión del crimen organizado, como de las propias autoridades locales y federales. A partir del estigma en términos goffmanianos, han logrado erigir una suerte de organización autogestiva tanto en la dimensión laboral como en la política, conformando cuadros políticos. Si bien el estigma de puta les ha obstaculizado esta tarea, la política de la identidad al ser excluidas y criminalizadas por el propio Estado, les permitió constituirse en 1994 como una brigada para establecerse como una organización con 
personalidad jurídica propia; el crecimiento de sus redes de apoyo les ha permitido ampliarse a nivel nacional para exigir reivindicaciones y enfrentarse a grupos fácticos. Sin embargo, no sólo han tenido que enfrentarse a gobiernos o criminalidad, sino también a algunas concepciones dentro de los propios feminismos, como el "neoabolicionismo" que ha permeado la narrativa gubernamental y que pasa a criminalizarlas por considerar su actividad como "explotación" y "trata". Así, han tenido que sortear violencias múltiples, desde políticas, económicas, legales, pero sobre todo simbólicas, que es donde radica una de sus tareas fundamentales, para vincularse con otros movimientos anticapitalistas como lo es el propio EZLN.

El coordinador Torres-Ruiz presenta en "AMLO y las jornadas antidesafuero", un recuento del claro proceso antidemocrático que se hizo en nombre de la propia democracia y la figura fetichizada del Estado de derecho por parte del bloque entonces hegemónico. Corría 2004 cuando el entonces presidente Fox buscaba desaforar al entonces jefe de Gobierno, López Obrador. Tras el anuncio y las artimañas institucionales ya conocidas, lo que el autor busca centrar no es el proceso "formal", sino la serie de repertorios sociales como la "Marcha del silencio", las pintas en casas o la apropiación por parte de diversos sectores sociales. En este punto reside la riqueza del texto, puesto que, de inspiración en Tilly, pone énfasis en los repertorios sociales y culturales que determinaron el fracaso del desafuero. Asimismo, señala las innovaciones políticas que permean el entendimiento de las izquierdas y derechas hasta nuestros días.

En esta misma línea Garza Zepeda entrega "¿Insurrección o democratización?”, donde analiza el papel de las luchas en Oaxaca de 2006 y los efectos no intencionales en el terreno de la democratización, tanto electoral como no electoral. No tanto causales, la lucha fue por recuperar la sujetidad politica. Recuperarse, como sujetos de su propio 
destino en un contexto autoritario. En consecuencia, la experimentación en nuevos modos de vida e imaginarios, los movimientos de ruptura, además de buscar encontrar el propio camino en la acción concreta, impulsan la creación de otros modos de organización colectiva por fuera de la democracia establecida que pueden $-\mathrm{O}$ no- manifestarse en la representatividad.

Otro texto más proviene de la pluma de Suaste, quien, con "Si Zapata viviera con los muertos estuviera", hace un breve recuento del MPJD, surgido a partir del asesinato del hijo del poeta Javier Sicilia y que logró, en su momento, formar una red bastante amplia para enfrentarse al entonces presidente Felipe Calderón y su política genocida. Este movimiento inicia con una movilización contra la política de muerte, necropolítica, administradora de las bajas a partir de masacres, pues los muertos son más que cifras: la politización de la víctima. Sin embargo, el desarrollo del movimiento fue de las organizaciones a la fragmentación y de la denuncia a la poca ejecución, lo cual permite ver al autor que el Estado no sólo no se debilitó ante las demandas, sino que permitió fortalecer su figura ante la disgregación y la ocupación misma de las víctimas, ante lo cual se inmuniza. Como resultado, los violentados siguen el camino de las violencias y el Estado se refuerza a partir de ellas.

Finalmente encontramos el capítulo de Álvarez y Fernández, quienes en "El recorrido de una propuesta: Del EZLN y el CNI al CIG", recapitulan las transformaciones del movimiento neozapatista y sus diversas presentaciones en contra del sistema de partidos como denunciando la hidra capitalista en la ampliación de propuestas alternativas a la modernidad occidental. Radical, este movimiento no busca tomar el poder o las instituciones, sino cambiar el mundo a través de llegar y formar redes con otros movimientos similares, como las mujeres kurdas, pero a partir de las demandas de los pueblos indígenas. 